\title{
RESEARCH
}

Open Access

\section{Descriptive epidemiology of changes in objectively measured sedentary behaviour and physical activity: six-year follow-up of the EPIC-Norfolk cohort}

Samantha Hajna ${ }^{1 *}$ (D), Tom White ${ }^{1}$, Søren Brage ${ }^{1}$, Esther M. F. van Sluijs ${ }^{1}$, Kate Westgate ${ }^{1}$, Andy P. Jones ${ }^{2}$, Robert Luben ${ }^{3}$, Kay-Tee Khaw ${ }^{3}$, Nicholas J. Wareham ${ }^{1}$ and Simon J. Griffin ${ }^{1,3}$

\begin{abstract}
Background: Sedentary time increases and total physical activity decreases with age. The magnitude and correlates of changes in sedentary time, light-intensity physical activity (LPA), moderate-to-vigorous intensity physical activity (MVPA), and overall physical activity remain unclear. We quantified these changes and identified their individual and sociodemographic correlates.

Methods: We used data from 1259 adults (67.8 \pm 6.9 years; $41.9 \%$ women) who participated in the EPIC-Norfolk Study. Activity was assessed at baseline (2004-2011) and follow-up (2012-2016) for 7 days using accelerometers. Potential correlates of change were specified a priori. We used unadjusted and adjusted sex-stratified linear regressions to identify correlates of change.

Results: Only 3.7\% of adults met the current MVPA recommendations. Sedentary time increased by $3.0 \mathrm{~min} /$ day/ year $(S D=12.3)$. $L P A, M V P A$, and overall PA decreased by $1.7 \mathrm{~min} /$ day/year $(S D=5.4), 3.0 \mathrm{~min} /$ day/year $(S D=6.0)$, and $8.8 \mathrm{cpm} /$ year $(S D=18.8)$, respectively. Correlates of greater rates of increase in sedentary time included older age and higher BMI in men, and older age, higher BMI, smoking, and urban dwelling in women. Correlates of greater rates of decrease in physical activity included older age, higher BMI, living alone, depression, car use, and/or fair/poor self-rated health in men, and older age, higher BMI, depression, smoking, and/or urban dwelling in women (e.g. depressed women had a $1.0 \mathrm{~min} /$ day/year greater rate of decline in MVPA than non-depressed women, $95 \% \mathrm{Cl}-1.8,-0.2)$.

Conclusions: Most (>95\%) adults are insufficiently active. Sedentary time increases and LPA, MVPA and overall physical activity decreases over time, with more pronounced rates of change observed in specific sub-groups (e.g. among older and depressed adults). To promote active living, the correlates of these changes should be considered in future interventions.
\end{abstract}

Keywords: Sedentary time, Physical activity, Accelerometry

\footnotetext{
* Correspondence: samantha.hajna@mrc-epid.cam.ac.uk

${ }^{1}$ MRC Epidemiology Unit, University of Cambridge, Cambridge, UK

Full list of author information is available at the end of the article
}

(c) The Author(s). 2018 Open Access This article is distributed under the terms of the Creative Commons Attribution 4.0 International License (http://creativecommons.org/licenses/by/4.0/), which permits unrestricted use, distribution, and reproduction in any medium, provided you give appropriate credit to the original author(s) and the source, provide a link to the Creative Commons license, and indicate if changes were made. The Creative Commons Public Domain Dedication waiver (http://creativecommons.org/publicdomain/zero/1.0/) applies to the data made available in this article, unless otherwise stated. 


\section{Background}

Achieving sufficient levels of physical activity is associated with decreased risk of chronic diseases (e.g. diabetes, cancer, depression) and premature mortality [1]. It is also associated with decreased risk of dementia, greater mobility, improved quality of life, and greater independence in later life [2-4]. Despite these benefits, it is estimated that $27.5 \%$ of adults are insufficiently active and at risk for inactivity-related health complications [5].

To inform the development and targeting of interventions designed to mitigate negative changes in activity, researchers have sought to quantify temporal changes in activity [6-9] and to identify their correlates [8-12]. For example, in a recent 10-year follow-up analysis of 962 participants of the Coronary Artery Risk Development in Young Adults (CARDIA) study [6], sedentary time was found to increase by $37.9 \mathrm{~min} /$ day, and light-intensity physical activity (LPA), unbouted moderate-to-vigorous intensity physical activity (MVPA), and total activity were found to decrease by $30.6 \mathrm{~min} /$ day, $7.5 \mathrm{~min} /$ day and $65.5 \mathrm{cpm}(17 \%)$ over a decade, respectively [6]. Changes in activity were patterned by race and sex [6]. While changes in physical activity and their correlates have been previously assessed, most studies, particularly those of older adults, have been restricted to the assessment of total physical activity volume $[8,9]$. Since sedentary behaviours and light-intensity physical activity (LPA) have important implications for health [13-15], more research on temporal changes across all ranges of activity intensity are needed.

Sedentary behaviours are any waking behaviours that are characterised by an energy expenditure $\leq 1.5$ metabolic-equivalent units (METs) and conducted in either a sitting, reclined, or lying down position (e.g. reading, watching television) [16]. LPA is any activity characterised by an energy expenditure between 1.5 and 3 METs and includes activities typical of routine daily activities (e.g. cooking, walking around the house) or low-intensity recreational and occupational activities (e.g. playing darts) [17]. Both lower levels of sedentary time and higher levels of LPA have been linked to decreased chronic disease risk [18-20]. Since decreasing sedentary time and increasing light-intensity activities may require only small changes to routine day-to-day activities, changing these activity intensities may be easier than increasing total activity volume or higher-intensity activity [13]. Quantifying changes in lower activity intensities and identifying the correlates of these changes may prove useful in identifying effective targets for intervention development and evaluation.

Our aim was to build on the existing literature base by estimating, in a population-based sample of middle-age and older English adults, six-year changes in sedentary time, light-intensity physical activity (LPA), moderate-to-vigorous intensity physical activity (MVPA), and overall physical activity using objective activity monitoring and to identify the individual and sociodemographic correlates of these changes.

\section{Methods}

We used data collected as part of the European Prospective Investigation of Cancer (EPIC)-Norfolk Study. In brief, 25,639 participants were recruited from 35 general practices and invited to attend a clinic assessment between 1993 and 1997. Participants were invited for second, third, and fourth in-clinic assessments between 1998 and 2000, 2004 and 2011, 2012 and 2016, respectively. Physical activity was assessed using accelerometers in the third and fourth assessments. For the purposes of this paper we refer to these 3rd and 4th health checks as the baseline and follow-up visits, respectively.

\section{Sedentary time and physical activity}

Participants wore an accelerometer (ActiGraph, Pensacola, FL) on their right hip for seven days excluding during bathing, swimming, or sleeping and returned their accelerometers to the research unit after the monitoring period using a postage paid envelope. Uniaxial accelerometers (GT1M; data recorded in five-second epochs) were worn at the baseline visit and triaxial accelerometers $(\mathrm{GT} 3 \mathrm{X}+$; data recorded at $100 \mathrm{~Hz})$ were worn at the follow-up visit. Harmonization of the GT1M and the GT3X+ data involved converting GT3X+ acceleration to counts in five-second epochs with the low-frequency extension filter disabled to match the on-board filtering performed by the GT1M firmware and retaining only the vertical axis data collected by the triaxial GT3X+ monitor (which is the measured axis in the uniaxial GT1M accelerometer); this method produces virtually identical results during standardised movements [21]. In addition, strong agreement has been previously demonstrated between these two accelerometers in human experiments both in terms of activity volume and intensity making them acceptable for use in a single study [17].

Only participants with $\geq 4$ valid days of data (weekend or weekday) at both baseline and follow-up were included in this study. A valid day was defined as having $\geq 600$ min of wear time in a day, with non-wear time defined as time segments with $\geq 90 \mathrm{~min}$ of continuous zero activity counts [22].

A review of the activity plots suggested that participants who wore their accelerometers for $\geq 19 \mathrm{~h} /$ day wore their accelerometers while sleeping. Since wear time may be correlated with our activity measures of interest, we excluded these participants to ensure the accurate assessment of activity levels and we also adjusted for wear time at baseline and follow-up in our regression analyses. Sedentary time, LPA, and MVPA were expressed 
in minutes/day and were classified according to the following counts per minute $(\mathrm{cpm})$ cut-offs: sedentary time $(<100 \mathrm{cpm})$, LPA (100 to $808 \mathrm{cpm})$, and MVPA $(\geq 809 \mathrm{cpm})$ [22]. The latter cut-point is based on the lower bound of MVPA identified in a study of older adults performing walking-based activities [23]. Overall physical activity (i.e. mean cpm) was defined as total activity counts divided by valid wear time.

The World Health Organization recommends that adults accumulate at least $150 \mathrm{~min}$ per week of MVPA in bouts of at least $10 \mathrm{~min}[5,24]$. We chose unbouted MVPA (i.e. cumulative MPVA) as our primary MVPA variable of interest because it also has benefits for health $[25,26]$ and may be easier for adults to accumulate than bouted MVPA. Nevertheless, to allow for the evaluation of activity profiles in the context of the current MVPA recommendations, we also present some descriptive statistics for bouted MVPA and regression estimates for the correlates of changes in bouted MVPA as a supplement. Bouted MVPA (min/day) was calculated as activity at an intensity $\geq 809 \mathrm{cpm}$ sustained for $10 \mathrm{~min}$ or more. Participants were classified as meeting MVPA guidelines if they accumulated $\geq 21.4 \mathrm{~min} /$ day of bouted MVPA (i.e. $\geq 150 \mathrm{~min} /$ week of MVPA).

\section{Individual and sociodemographic factors}

We identified factors for inclusion into this study based on a priori evidence that they may be correlated with sedentary time and/or physical activity [11, 27-30] and thus, we hypothesized, may also be potentially important baseline predictors of changes in these activities over time. Table 1 includes a summary of the individual and sociodemographic factors that were assessed in this study. With the exception of body mass index (BMI; kg/ $\mathrm{m}^{2}$ ), which was calculated based on height and weight measurements collected by trained research assistants, all of the individual and sociodemographic factors were assessed via a standardised questionnaire. Follow-up time was calculated as the difference in years between the baseline and follow-up visits.

\section{Statistical analyses}

We calculated descriptive statistics for all of the variables of interest at baseline and follow-up, overall and by sex. Given that the predictors of activity change may differ between men and women, we used sex-stratified linear regression models to estimate the associations between each of the individual and sociodemographic factors at baseline (exposures) and rates of change in the activity measures (outcomes), unadjusted and mutually adjusted for all of the individual/sociodemographic variables of interest, season at baseline and follow-up assessments, wear time at baseline and follow-up, and baseline activity. We adjusted for the individual and sociodemographic factors as assessed at baseline in order to evaluate the role of these factors on change in activity. We expressed the outcomes as rates of change per year (i.e. min/day/year for sedentary time, LPA and MVPA, and counts/minute/year for overall PA) in order to account for variations in follow-up time. Given that wear time could be correlated with measures of activity, we conducted sensitivity analyses additionally adjusting for differences in wear time between baseline and follow-up to ensure that these differences were not responsible for the observed changes in activity. All analyses were based on complete case data and were conducted using Stata/ SE 14.1 (College Station, TX: StataCorp LP).

\section{Findings}

Of the 8623 adults who attended the baseline visit and the 5693 adults who attended the follow-up visit, 4169 (48.3\%) and 5504 (96.7\%) participants, respectively, wore an accelerometer for 7 days following their in-clinic visit. A total of 1813 participants had accelerometer data at both visits. Of these, 154 had invalid data at baseline and/or follow-up (i.e. $<4$ valid days of data, data collected at a different epoch lengths, or $\geq 19 \mathrm{~h}$ /day of wear-time), leaving complete accelerometer data for 1659 participants. Of these, 1259 participants (75.9\%) had complete data on the exposures, outcomes, and covariates of interest. Compliance with the accelerometry protocol was high, with $99 \%$ of participants wearing their monitors for at least $12 \mathrm{~h} /$ day and $89.5 \%$ of participants wearing their monitors between 13 and $16 \mathrm{~h}$ per day. There was a small difference in wear-time between baseline and follow-up, with participants at baseline and follow-up wearing their accelerometers for an average of $14.5(\mathrm{SD}=0.9)$ and $14.3 \mathrm{~h} /$ day $(\mathrm{SD}=0.9)$, respectively (mean difference: $0.16 \mathrm{~h} /$ day, $95 \%$ CI $0.11,0.21$ ).

\section{Descriptive characteristics}

The characteristics of the study population at baseline are presented overall, and by sex in Table 1 . In brief, participants were on average 67.8 years of age (SD 6.9; Range: 49 to 91 ) and overweight (mean BMI: $26.4 \mathrm{~kg} /$ $\mathrm{m}^{2}, \mathrm{SD}=4.2$ ). The majority had an A-level education or higher, did not have a paid job, and were married or living with a partner. Average follow-up time was 5.7 years ( $\mathrm{SD}=1.9$; Range 1.8 to 9.4 years).

The participants who were included in our analyses were younger, more likely to be educated to an A-level or higher, more likely to have a paid job, more likely to be married/living with a partner, more likely to use a car as a primary mode of transport outside of work, had better self-rated health, and were less sedentary and more active than those who were excluded (Additional file 1: Table S1). 
Table 1 Characteristics of the EPIC-Norfolk study sample at baseline, overall and by sex

\begin{tabular}{|c|c|c|c|}
\hline & Overall & Men & Women \\
\hline & $n=1259$ & $n=528$ & $n=731$ \\
\hline & \multicolumn{3}{|l|}{ mean (SD) } \\
\hline Age, years (Range: 49 to 91 years) & $67.8(6.9)$ & $68.9(6.9)$ & $66.9(6.8)$ \\
\hline \multirow[t]{2}{*}{ Body mass index, $\mathrm{kg} / \mathrm{m}^{2}$} & $26.4(4.2)$ & $26.7(3.4)$ & $26.2(4.7)$ \\
\hline & \multicolumn{3}{|l|}{$\%(n)$} \\
\hline \multicolumn{4}{|l|}{ Education level $^{a}$} \\
\hline O-level or lower & $34.4(433)$ & $27.7(146)$ & $39.3(287)$ \\
\hline A-level & $47.2(594)$ & $52.4(277)$ & $43.4(317)$ \\
\hline Degree & $18.4(232)$ & $19.9(105)$ & $17.4(127)$ \\
\hline \multicolumn{4}{|l|}{ Paid job at present } \\
\hline Yes & $28.4(357)$ & $31.8(168)$ & $25.9(189)$ \\
\hline No & $71.6(902)$ & $68.2(360)$ & $74.1(542)$ \\
\hline \multicolumn{4}{|l|}{ Marital status } \\
\hline Married/living with partner & $83.1(1046)$ & $90.3(477)$ & $77.8(569)$ \\
\hline Single/widowed/separated/divorced & 16.9 (213) & $9.7(51)$ & $22.2(162)$ \\
\hline \multicolumn{4}{|c|}{ Self-reported depression requiring treatment } \\
\hline Yes & $21.7(273)$ & $14.4(76)$ & $26.9(197)$ \\
\hline No & $78.3(986)$ & $85.6(452)$ & $73.1(534)$ \\
\hline \multicolumn{4}{|l|}{ Household dog ownership } \\
\hline Yes & $19.4(244)$ & $17.8(94)$ & $20.5(150)$ \\
\hline No & $80.6(1015)$ & $82.2(434)$ & $79.5(581)$ \\
\hline \multicolumn{4}{|l|}{ Primary mode of transport outside of work } \\
\hline Car & $88.6(1116)$ & $90.7(479)$ & $87.1(637)$ \\
\hline Walking, public transport or cycling & $11.4(143)$ & $9.3(49)$ & $12.9(94)$ \\
\hline \multicolumn{4}{|l|}{ Smoking status } \\
\hline Current & $2.6(33)$ & $1.9(10)$ & $3.1(23)$ \\
\hline Former/never & $97.4(1226)$ & $98.1(518)$ & $96.9(708)$ \\
\hline \multicolumn{4}{|l|}{ Self-rated health } \\
\hline Very good/excellent/good & $89.0(1121)$ & $88.8(469)$ & $89.2(652)$ \\
\hline Fair/poor & $11.0(138)$ & $11.2(59)$ & $10.8(79)$ \\
\hline \multicolumn{4}{|l|}{ Home neighbourhood location ${ }^{\text {b }}$} \\
\hline Urban & $53.1(669)$ & $54.9(290)$ & $51.8(379)$ \\
\hline Rural & $46.9(590)$ & $45.1(238)$ & $48.2(352)$ \\
\hline
\end{tabular}

${ }^{a}$ Education categories are roughly analogous to high school, college, and university; Percentages (\%) may not add to $100.0 \%$ due to rounding

$\mathrm{b}$ Based on self-reported home postcode address

\section{Accelerometer-assessed activity}

At baseline, participants accumulated an average of $11.2 \mathrm{~h} /$ day of sedentary time $(\mathrm{SD}=1.1), 1.8 \mathrm{~h} /$ day of LPA $(\mathrm{SD}=0.4)$, and $1.5 \mathrm{~h} /$ day of unbouted MVPA $(\mathrm{SD}=0.6)$. Only $3.7 \%$ of participants $(6.1 \%$ men; $2.1 \%$ women) accumulated the recommended level of $150 \mathrm{~min} /$ week of MVPA in bouts of at least $10 \mathrm{~min}$. At follow-up, participants accumulated an average of $11.4 \mathrm{~h} /$ day of sedentary time $(\mathrm{SD}=1.0), 1.6 \mathrm{~h} /$ day of LPA $(\mathrm{SD}=0.5)$, and $1.3 \mathrm{~h} /$ day of unbouted MVPA $(\mathrm{SD}=0.6)$. Similar to the levels observed at baseline, only $3.7 \%$ of participants $(4.7 \%$ men; $2.9 \%$ women $)$ accumulated the recommended level of $150 \mathrm{~min} /$ week of MVPA in bouts of at least $10 \mathrm{~min}$ at follow-up. Women accumulated 29.7 fewer $\mathrm{min} /$ day of sedentary time $(95 \%$ CI $-36.6,-22.7)$ and 13.4 more min/day of LPA than men (95\% CI 10.4, 16.3) at baseline. These differences were also observed at follow-up, with women accumulating 22.9 fewer $\mathrm{min} /$ day of sedentary time $(95 \% \mathrm{CI}-29.7,-16.0)$ and 14.5 more $\mathrm{min} /$ day of LPA than men $(95 \%$ CI 11.5 , 17.4). There were no conclusive differences between 
men and women in levels of MVPA and overall physical activity at baseline or follow-up (Fig. 1).

\section{Changes in accelerometer-assessed activity}

Sedentary time increased by $3.0 \mathrm{~min} /$ day/year $(\mathrm{SD}=$ 12.3) and LPA, and unbouted MVPA decreased by 1.7 $(\mathrm{SD}=5.4), 3.0 \mathrm{~min} /$ day/year $\quad(\mathrm{SD}=6.0)$, respectively. Overall physical activity decreased by $8.8 \mathrm{cpm} /$ year (SD $=18.8$ ). This corresponded to participants increasing the percentage of time they spent in sedentary time by $2.7 \%$ (77.1 to $79.8 \%$ ), and decreasing the amount of time that they spent in LPA and unbouted MVPA by $0.9 \%$ (12.3 to $11.4 \%$ ) and $1.8 \%$ (10.6 to $8.8 \%$ ), respectively. Changes were similar in men and women (Fig. 1), but there was evidence that rates of change varied by age group with rates of change more pronounced in adults $\geq 65$ than in adults $<65$ years (Additional file 1: Table S2). For example, MVPA decreased at a rate of $3.7 \mathrm{~min} /$ day/year in men $\geq 65$ years but at a rate of $2.2 \mathrm{~min} /$ day/year in men $<65$ years, representing a difference of $-1.5 \mathrm{~min} /$ day/ year $(95 \%$ CI $-2.6,-0.4)$.

\section{Correlates of change}

Older age and higher BMI were associated with a greater rate of increase in sedentary time and greater rates of decline in LPA, MVPA, and overall physical activity in both men and women. The only exception was for the
BMI-MVPA association, which did not appear to be important in women (Table 2). Among men, being married/living with a partner was associated with a $1.8 \mathrm{~min} /$ day/year smaller rate of decline in LPA (95\% CI 0.5, 3.1), having very good/excellent/good (versus fair or poor) self-reported health was associated with a $1.3 \mathrm{~min} /$ day/ year smaller rate of decline in LPA (95\% CI 0.1, 2.6), being depressed was associated with a greater rate of decline in MVPA (-1.5 min/day/year, 95\% CI -2.7, - 0.2) and overall physical activity $(-5.8 \mathrm{cpm} /$ year; $95 \% \mathrm{CI}$ $-10.4,-1.3$ ), and relying on a car (as opposed to walking, public transport, or cycling) was associated with $1.6 \mathrm{~min} /$ day/year greater rate of decline in MVPA (95\% CI -3.2, - 0.03). Among women, being a current smoker was associated with a $3.6 \mathrm{~min} /$ day/year greater rate of increase in sedentary time (95\% CI 0.04, 7.2), living in an urban neighbourhood was associated with a $2.4 \mathrm{~min} /$ day/year greater rate of increase in sedentary time (95\% CI 1.0, 3.7), being depressed was associated with a $1.0 \mathrm{~min} /$ day/year greater rate of decline in MVPA $(95 \%$ CI -1.8, - 0.2), being a current smoker was associated with a $8.6 \mathrm{cpm} /$ year greater rate of decline in overall physical activity $(95 \%$ CI $-14.9,-2.2)$, and living in an urban neighbourhood was associated with a greater rate of decline in MVPA and overall physical activity ($1.1 \mathrm{~min} /$ day/year, $95 \%$ CI $-1.9,-0.3 ;-3.3 \mathrm{cpm} /$ year, $95 \%$ CI -5.7, - 0.9). In models of MVPA accumulated in
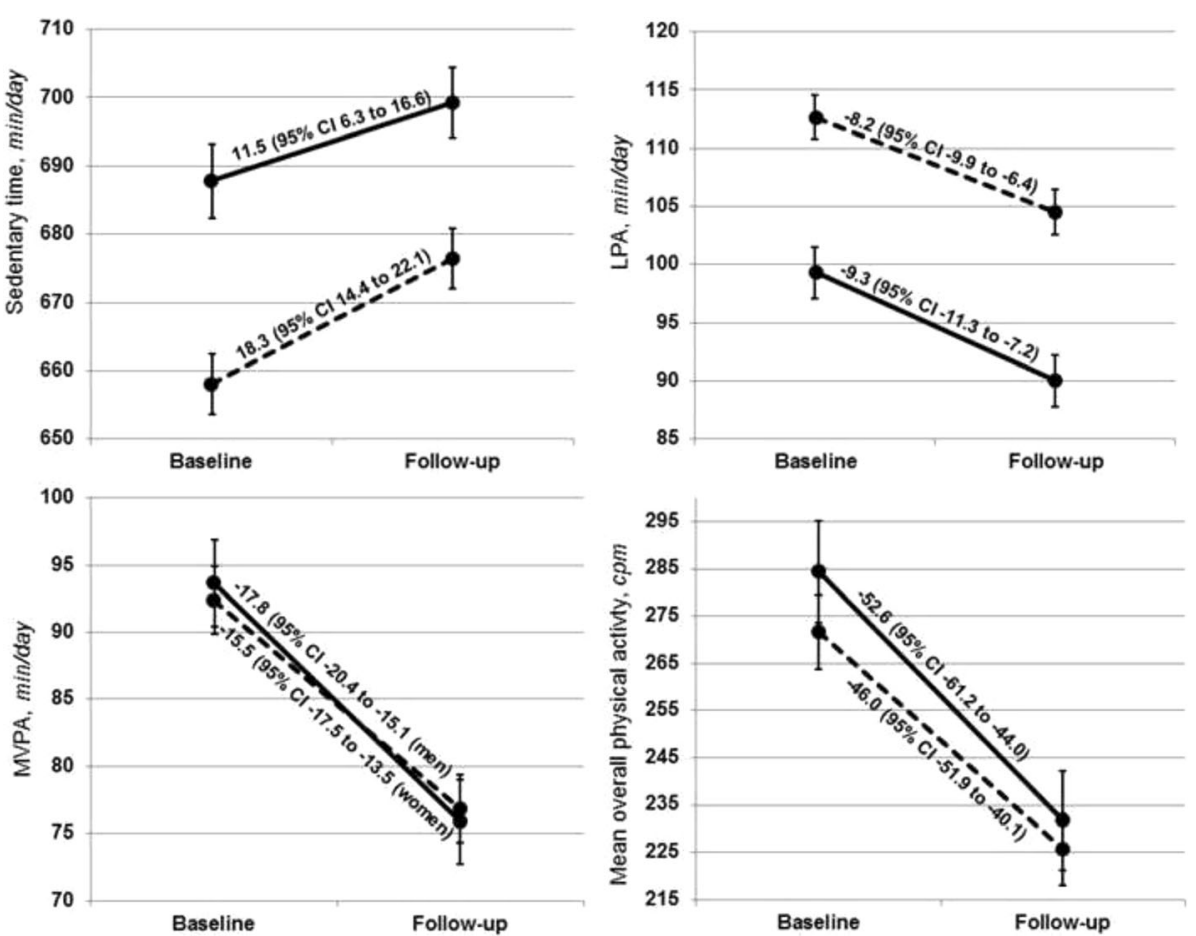

Fig. 1 Mean levels of accelerometer-assessed sedentary time, light-intensity physical activity (LPA), moderate-to-vigorous intensity physical activity (MVPA), and overall physical activity (95\% confidence intervals) in men and women at baseline and at follow-up with corresponding changes in activity levels (men: bold line; women; dashed line) 


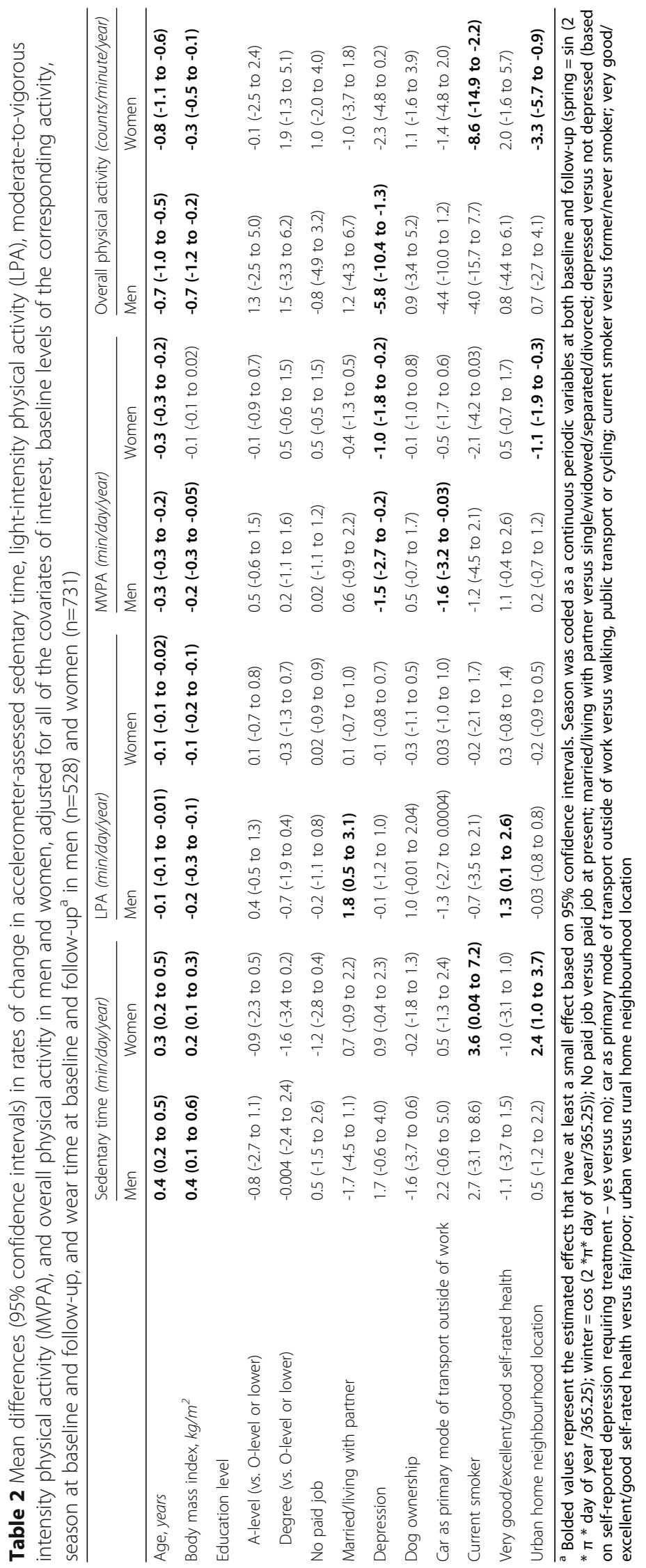


bouts $\geq 10$ min (Additional file 1: Table S3), only older age was associated with a greater rate of decline in MVPA in women. Only some of the associations that were observed in the adjusted models (Table 2) were also observed in the unadjusted models (Additional file 1: Table S4).

\section{Discussion}

Only $3.7 \%$ of our sample of older adults met the current MVPA recommendation. Sedentary time increased by $3.0 \mathrm{~min} /$ day/year, whereas LPA, unbouted MVPA and overall physical activity decreased by $1.7 \mathrm{~min} /$ day/year, $3.0 \mathrm{~min} /$ day/year, and $8.8 \mathrm{cpm} /$ year, respectively. Although men accumulated more sedentary time and less LPA than women, there were no conclusive differences between men and women in unbouted MVPA or overall physical activity or in changes in any of the activity measures of interest. There were, however, more pronounced rates of change in activity levels in adults $\geq 65$ than those $<65$ years. Correlates of greater rates of increase in sedentary time included older age and higher BMI in men, and older age, higher BMI, smoking, and urban dwelling in women. Correlates of greater rates of decrease in physical activity included older age, higher BMI, living alone, depression, car use, and poor/fair self-rated health car use in men, and older age, higher BMI, depression, smoking, and urban dwelling in women.

Our findings are consistent with those of previous studies in which activity was assessed via questionnaires $[10,11]$ and accelerometers [6-9]. For example, in an analysis of 3334 participants of the EPIC-Norfolk Study during their transition into retirement, self-reported overall activity, transport-related activity, and occupational-related activity decreased, whereas recreational activity, household-related activity, and TV viewing time increased [10]. Similarly, increases in sedentary time and LPA, and decreases in MVPA were observed over 10 years of follow-up in analyses of 5022 older adults who participated in the English Longitudinal Study of Ageing [11]. In this study, correlates of declining physical activity included older age, female sex, having ever smoked, long-standing illness, arthritis, obesity, and depressive symptoms, and lower wealth. In an analysis of 519 community dwelling older adults who participated in the Rush Memory and Aging Project (Chicago, USA), and in whom activity was assessed using accelerometers, total activity declined by approximately $2 \%$ per year, with daily activity declining 3\% more rapidly for every one-year increase in age and 6\% more slowly for every additional year of education [8]. Similarly, in an analysis of 339 community dwelling older adults who participated in the Physical Activity Cohort Study (Tayside, Scotland), total accelerometer-assessed activity declined by $6.2 \%$ per year [9].
While previous studies have quantified changes in activity and their correlates, no previous study has, to our knowledge, examined both changes and correlates of these changes in relation to accelerometer-assessed activity volume and a range of activity intensities in both middle-aged and older adults. Our study adds to the current literature by providing an examination of changes during middle and later adulthood in sedentary time, LPA, MVPA, and overall PA and the correlates of these changes. This information may help in the evaluation of interventions and in informing the development of new interventions. For example, we found an annual decrease in MVPA of $3.0 \mathrm{~min} /$ day, suggesting a loss of $15 \mathrm{~min} /$ day MVPA over a five-year time period. A smaller change in MVPA was observed in the CARDIA study (i.e. a $7.5 \mathrm{~min} /$ day decline in MVPA over 10 years of follow-up) [6]. The difference between our finding and the finding from the CARDIA study is likely a result of the CARDIA population being younger. The magnitude of decline that we observed in MVPA is likely to be of clinical significance in our population [31-33]. For example, each additional $10 \mathrm{~min} /$ day in MVPA has been associated with a $8 \%$ decreased risk of all-cause mortality in older British men after adjustment for age, region of residence, season of accelerometer wear, accelerometer wear time, social class, alcohol use, smoking status, sleep time, living alone status, body mass index, and mobility disability (Hazard Ratio $=0.92,95 \%$ CI 0.86, 0.98) [31].

In terms of informing the development of interventions, our findings demonstrate that changes in activity intensities are comparable between men and women but that rates of change are more pronounced among older adults and that correlates of change appear to be sex-specific. This suggests that intervening on activity changes during older age may need to be a priority and that targeted interventions may be needed to effectively attenuate negative changes in activity in both men and women. We also identified more individual and sociodemographic correlates for unbouted than bouted MVPA. This suggests that mitigating changes in unbouted and bouted MVPA may require intervening on a different set of factors.

Strengths of our study included objective activity monitoring of a large sample of adults over a relatively long period. When interpreting the results, several limitations should also be noted. Firstly, the subset of EPIC-Norfolk participants who were included in our analyses were healthier than the EPIC-Norfolk participants who were excluded. This limits the degree to which our findings can be generalised to other populations, including to the broader EPIC-Norfolk population. Secondly, we aimed to provide an evaluation of the individual and sociodemographic correlates of activity change among older adults. Further research is needed to identify other 
factors that may influence the trajectory of activity behaviours in later life (e.g. neighbourhood characteristics, attitudes towards activity behaviours) and their interactions. Thirdly, the association observed between smoking and overall physical activity in women should be interpreted with caution; this could have been a spurious finding attributable to the rarity of smoking in our population. Fourthly, we cannot rule out the possibility that there may be rare instances in which the method of identifying non-wear by consecutive zero counts may result in prolonged sedentary time being mistaken for non-wear time.

In conclusion, we demonstrated that sedentary time increases and activity levels decreases over time, with more pronounced rates of change observed in specific sub-groups (e.g. among older and depressed adults). The individual and sociodemographic correlates of activity change appear to be sex-specific. Targeting these correlates in future interventions may help limit increases in sedentary time and decreases in physical activity among English adults.

\section{Additional file}

Additional file 1: Table S1. Baseline characteristics of the participants who only attended the baseline visit and participants who attended both the baseline and follow-up visits and had complete accelerometry data at both visits. Table $\mathbf{S 2}$. Normalised mean rates of change in activity between baseline and follow-up in younger and older men and women with corresponding mean differences between age groups (95\% confidence intervals). Table S3. Mean differences in rates of change in accelerometer-assessed moderate-to-vigorous intensity physical activity (min/day/year) accumulated in bouts $\geq 10 \mathrm{~min}$ ( $95 \%$ confidence intervals) in men and women, unadjusted and maximally adjusted for all of the covariates of interest, baseline levels of the corresponding activity, season, and baseline and follow-up wear-time. ${ }^{\mathrm{a}}$. Table S4. Unadjusted mean differences in rates of change in accelerometer-assessed sedentary time, light-intensity physical activity (LPA), moderate-to-vigorous intensity physical activity (MVPA), and overall physical activity ( $95 \%$ confidence intervals) in men and women. ${ }^{\mathrm{a}}$ (DOCX $32 \mathrm{~kb}$ )

\section{Acknowledgements}

The authors would like to thank Stephen Sharp, Fumiaki Imamura, Antonia Smith, Lewis Griffiths and Carolyn Brechin from the University of Cambridge for their statistical, data processing, and data management support. The authors would also like to thank the entire EPIC-Norfolk Study team for their role in data collection, all of the individuals who were involved in securing funding and collecting data for the express purpose of investigating the determinants of activity among older adults, and all of the EPIC-Norfolk Study participants for making this work possible.

\section{Funding}

This work was supported by the Lifelong Health and Wellbeing CrossCouncil Programme (MR/K025147/1 to SJG, NJW and AJ), the Medical Research Council (MRC) (MC_UU_12015/4 to SJG, MC_UU_12015/3 to SB, MC_UU_12015/7 to EvS, MC_UU_12015/1 to NJW), the Canadian Institutes of Health Research (FRN 146766; Fellowship to SH), and Medlmmune (Studentship to TW). The EPIC-Norfolk study is supported by programme grants from the Medical Research Council (G0401527) and Cancer Research UK (C864) A8257) and Age UK (Grant reference: 262). The work was supported by the Centre for Diet and Activity Research (CEDAR), a UKCRC Public Health Research Centre of Excellence which is funded by the British Heart Foundation, Cancer Research UK, Economic and Social Research Council, Medical
Research Council, the National Institute for Health Research, and the Wellcome Trust (087636/Z/08/Z; ES/G007462/1; MR/K023187/1). The University of Cambridge has received salary support in respect of SJG from the NHS in the East of England through the Clinical Academic Reserve. The views expressed are those of the authors and not necessarily those of the NHS or the Department of Health.

\section{Availability of data and materials}

The datasets generated and/or analysed during the current study are not publicly available as per the rules and regulations of the MRC Epidemiology Unit and the University of Cambridge.

\section{Authors' contributions}

NJW and KTK are the Principal Investigators of the EPIC-Norfolk study and led the phases of the cohort study on which this specific analysis is based. $\mathrm{SH}$ wrote the manuscript and conducted the statistical analyses. TW assisted with the processing of the accelerometry data and the interpretation of the study results. $\mathrm{KW}$ processed the accelerometry data and $\mathrm{RL}$ led the management of the EPIC-Norfolk data. All of the authors contributed to the editing of the manuscript, assisted in the interpretation of the results, and approved the final manuscript.

\section{Ethics approval and consent to participate}

All participants provided written informed consent The EPIC-Norfolk was approved by the Norwich District Health Authority ethics committee.

\section{Consent for publication}

Not applicable.

\section{Competing interests}

The authors declare that they have no competing interests.

\section{Publisher's Note}

Springer Nature remains neutral with regard to jurisdictional claims in published maps and institutional affiliations.

\section{Author details}

${ }^{1}$ MRC Epidemiology Unit, University of Cambridge, Cambridge, UK. ${ }^{2}$ Norwich Medical School, University of East Anglia, Norwich, UK. ${ }^{3}$ Department of Public Health and Primary Care, University of Cambridge, Cambridge, UK.

Received: 21 May 2018 Accepted: 4 November 2018

Published online: 27 November 2018

\section{References}

1. Warburton DER, Nicol CW, Bredin SSD. Health benefits of physical activity: the evidence. Can Med Assoc J. 2006;174:801-9. https://doi.org/10.1503/ cmaj.051351.

2. Balboa-Castillo T, Leon-Munoz LM, Graciani A, Rodriguez-Artalejo F, GuallarCastillon P. Longitudinal association of physical activity and sedentary behavior during leisure time with health-related quality of life in community-dwelling older adults. Heal Qual Life Outcomes. 2011;9:47. https://doi.org/10.1186/1477-7525-9-47

3. Gill TM, Guralnik JM, Pahor M, Church T, Fielding RA, King AC, et al. Effect of structured physical activity on overall burden and transitions between states of major mobility disability in older persons: secondary analysis of a randomized trial. Ann Intern Med. 2016;165:833-40. https://doi.org/10.7326/ M16-0529.

4. Frankish $\mathrm{H}$, Horton R. Prevention and management of dementia: a priority for public health. Lancet. 2017. https://doi.org/10.1016/S01406736(17)31756-7.

5. Guthold R, Stevens GA, Riley LM, Bull FC. Articles Worldwide trends in insufficient physical activity from 2001 to 2016: a pooled analysis of 358 population-based surveys with 1.9 million participants; 2018. https://doi.org/ 10.1016/S2214-109X(18)30357-7.

6. Gabriel KP, Sidney S, Jacobs DR Jr, Whitaker KM, Carnethon MR, Lewis CE, et al. 10-year changes in accelerometer-based physical activity and sedentary time during midlife: CARDIA study. Am J Epidemiol. 2018. https://doi.org/10. 1093/aje/kwy117. 
7. Keadle SK, Shiroma EJ, Kamada M, Matthews CE, Harris TB, Lee I-M Reproducibility of accelerometer-assessed physical activity and sedentary time. Am J Prev Med. 2017;52:541-8. https://doi.org/10.1016/j.amepre.2016.11.010.

8. Buchman AS, Wilson RS, Yu L, James BD, Boyle PA, Bennett DA. Total daily activity declines more rapidly with increasing age in older adults. Arch Gerontol Geriatr. 2014:58:74-9. https://doi.org/10.1016/j.archger.2013.08.001.

9. Clarke CL, Sniehotta FF, Vadiveloo T, Argo IS, Donnan PT, MCMurdo MET, et al. Factors associated with change in objectively measured physical activity in older people - data from the physical activity cohort Scotland study. BMC Geriatr. 2017;17:180. https://doi.org/10.1186/s12877-017-0578-1.

10. Barnett I, van Sluijs E, Ogilvie D, Wareham NJ. Changes in household, transport and recreational physical activity and television viewing time across the transition to retirement: longitudinal evidence from the EPICNorfolk cohort. J Epidemiol Community Heal. 2014;68:747-53. https://doi. org/10.1136/jech-2013-203225.

11. Smith L, Gardner B, Fisher A, Hamer M. Patterns and correlates of physical activity behaviour over 10 years in older adults: prospective analyses from the English longitudinal study of ageing. BMJ Open. 2015;5:e007423. https:// doi.org/10.1136/bmjopen-2014-007423.

12. Barnett I, van Sluijs EM, Ogilvie D. Physical activity and transitioning to retirement: a systematic review. Am J Prev Med. 2012;43:329-36. https://doi. org/10.1016/j.amepre.2012.05.026.

13. Sparling PB, Howard BJ, Dunstan DW, Owen N. Recommendations for physical activity in older adults. BMJ. 2015;350:h100. https://doi.org/10.1136/bmj.h100.

14. Owen N, Sparling PB, Healy GN, Dunstan DW, Matthews CE. Sedentary behavior: emerging evidence for a new health risk. Mayo Clin Proc. 2010

15. Füzéki E, Engeroff T, Banzer W. Health benefits of light-intensity physical activity: a systematic review of accelerometer data of the National Health and nutrition examination survey (NHANES). Sports Med. 2017.

16. Day N, Oakes S, Luben R, Khaw KT, Bingham S, Welch A, et al. EPIC-Norfolk: study design and characteristics of the cohort. European Prospective Investigation of Cancer. Br J Cancer. 1999;80(Suppl 1):95-103. http://www.srl. cam.ac.uk/epic/publications/day_bjc_1999_clean.pdf.

17. Robusto KM, Trost SG. Comparison of three generations of ActiGraph activity monitors in children and adolescents. J Sport Sci. 2012;30:1429-35. https://doi.org/10.1080/02640414.2012.710761.

18. Mankowski RT, Aubertin-Leheudre M, Beavers DP, Botoseneanu A, Buford TW, Church T, et al. Sedentary time is associated with the metabolic syndrome in older adults with mobility limitations--the LIFE study. Exp Gerontol. 2015;70:32-6. https://doi.org/10.1016/j.exger.2015.06.018.

19. Bann D, Hire D, Manini T, Cooper R, Botoseneanu A, McDermott MM, et al. Light intensity physical activity and sedentary behavior in relation to body mass index and grip strength in older adults: cross-sectional findings from the lifestyle interventions and Independence for elders (LIFE) study. PLoS One. 2015;10:e0116058. https://doi.org/10.1371/journal.pone.0116058.

20. Parsons TJ, Sartini C, Ellins EA, JPJ H, Smith KE, Ash S, et al. Objectively measured physical activity, sedentary time and subclinical vascular disease: Cross-sectional study in older British men; 2016. https://doi.org/10.1016/j. ypmed.2016.05.031.

21. Ried-Larsen M, Brond JC, Brage S, Hansen BH, Grydeland M, Andersen LB, et al. Mechanical and free living comparisons of four generations of the Actigraph activity monitor. Int J Behav Nutr Phys Act. 2012;9:113. https://doi. org/10.1186/1479-5868-9-113.

22. Berkemeyer K, Wijndaele K, White T, Cooper AJ, Luben R, Westgate K, et al. The descriptive epidemiology of accelerometer-measured physical activity in older adults. Int J Behav Nutr Phys Act. 2016;13:2. https://doi.org/10.1186/ s12966-015-0316-Z

23. Hall KS, Howe CA, Rana SR, Martin CL, Morey MC. METs and accelerometry of walking in older adults: standard versus measured energy cost. Med Sci Sport Exerc. 2013;45:574-82. https://doi.org/10.1249/MSS.0b013e318276c73c.

24. WHO | Physical Activity and Adults. WHO. 2015. http://www.who.int/ dietphysicalactivity/factsheet_adults/en/. Accessed 15 Sep 2018.

25. Loprinzi PD, Davis RE. Bouted and non-bouted moderate-to-vigorous physical activity with health-related quality of life. Prev Med Rep. 2016;3:468. https://doi.org/10.1016/j.pmedr.2015.12.005

26. Hajna S, Ross NA, Dasgupta K. Steps, moderate-to-vigorous physical activity, and cardiometabolic profiles. Prev Med. 2018;107:69-74. https://doi.org/10. 1016/j.ypmed.2017.11.007.

27. Espinel PT, Chau JY, van der Ploeg HP, Merom D. Older adults' time in sedentary, light and moderate intensity activities and correlates: application of Australian time use survey. J Sci Med Sport. 2015;18:161-6. https://doi. org/10.1016/j.jsams.2014.02.012.

28. Wu YT, Luben $R$, Jones A. Dog ownership supports the maintenance of physical activity during poor weather in older English adults: cross-sectional results from the EPIC Norfolk cohort. J Epidemiol Community Heal. 2017. https://doi.org/10.1136/jech-2017-208987.

29. Fan JX, Wen M, Kowaleski-Jones L. Rural-urban differences in objective and subjective measures of physical activity: findings from the National Health and nutrition examination survey (NHANES) 2003-2006. Prev Chronic Dis. 2014;11:E141. https://doi.org/10.5888/pcd11.140189.

30. Shoham DA, Dugas LR, Bovet P, Forrester TE, Lambert EV, Plange-Rhule J, et al. Association of car ownership and physical activity across the spectrum of human development: modeling the epidemiologic transition study (METS). BMC Public Health. 2015;15:173. https://doi.org/10.1186/s12889-015-1435-9.

31. Jefferis BJ, Parsons TJ, Sartini C, Ash S, Lennon LT, Papacosta O, et al. Objectively measured physical activity, sedentary behaviour and all-cause mortality in older men: does volume of activity matter more than pattern of accumulation? Br J Sports Med. 2018;1-8. https://doi.org/10.1136/bjsports2017-098733.

32. Wen CP, Wai JPM, Tsai MK, Yang YC, Cheng TYD, Lee MC, et al. Minimum amount of physical activity for reduced mortality and extended life expectancy: a prospective cohort study. Lancet. 2011.

33. Sabia S, Dugravot A, Kivimaki M, Brunner E, Shipley MJ, Singh-Manoux A. Effect of intensity and type of physical activity on mortality: results from the Whitehall II cohort study. Am J Public Health. 2012

Ready to submit your research? Choose BMC and benefit from:

- fast, convenient online submission

- thorough peer review by experienced researchers in your field

- rapid publication on acceptance

- support for research data, including large and complex data types

- gold Open Access which fosters wider collaboration and increased citations

- maximum visibility for your research: over $100 \mathrm{M}$ website views per year

At BMC, research is always in progress.

Learn more biomedcentral.com/submissions 